\begin{tabular}{|} 
Ambiente \& Água - An Interdisciplinary Journal of Applied Science \\
ISSN 1980-993X - doi:10.4136/1980-993X \\
www.ambi-agua.net \\
E-mail: ambi-agua@agro.unitau.br
\end{tabular}

\title{
Avaliação de sistemas de gestão ambiental em granjas de suínos
}

\author{
doi: 10.4136/ambi-agua.1504
}

Received: 14 Sep. 2014; Accepted: 22 Oct. 2014

\author{
Bruno Vieira de Carvalho; Angelita Pereira Melo e Sousa; \\ Francisco Rafael Martins Soto ${ }^{*}$ \\ Instituto Federal de Educação, Ciência e Tecnologia de São Paulo (IFSP-SRQ), São Roque, SP, Brasil \\ *Autor correspondente: e-mail: chicosoto34@gmail.com, \\ brunov.carvalho94@gmail.com, angelmelo83@gmail.com
}

\section{RESUMO}

Considerando os impactos ambientais causados pela criação intensiva de suínos, a importância econômica e crescimento desta atividade, este estudo teve como objetivo avaliar o uso de boas práticas de gestão ambiental em granjas localizadas no Estado de São Paulo/Brasil. Para isto, entrevistas exploratórias foram realizadas com gerentes ou proprietários de 37 granjas escolhidas aleatoriamente. A partir dos dados obtidos, foi possível elaborar um questionário com oito perguntas e criar um banco de dados eletrônico contendo perguntas e respostas. Para cada processo realizado nas granjas, foram atribuídos pesos de 1 a 10 de acordo com sua importância em prevenir ou atenuar a degradação ambiental. As granjas foram, então, classificadas como satisfatórias, satisfatórias com restrições e insatisfatórias se suas pontuações fossem maiores ou iguais a 70 pontos, entre a 51 e 69 pontos ou inferiores a 51 pontos, respectivamente. Os resultados mostraram que aproximadamente $62 \%$ das granjas investigadas foram consideradas insatisfatórias uma vez que tiveram pontuação média de 43,61 pontos. Aproximadamente $11 \%$ e $27 \%$ foram satisfatórias com restrições e satisfatórias, respectivamente, à medida que tiveram pontuações de 59,50 e 84,40 pontos. Para os itens considerados importantes, como o uso de biodigestores e práticas de compostagem, 51,35\% não possuíam biodigestores e 67,55\% e 62,15\%, respectivamente, não utilizavam práticas de compostagem ou o faziam de forma insatisfatória. Ficou evidente então a necessidade de criação de programas de incentivo para melhoria no manejo dos resíduos de suínos em granjas do estado de São Paulo.

Palavras-chave: biodigestor, compostagem, dejeto suíno.

\section{Evaluation of environmental management systems on swine farms}

\begin{abstract}
Due to the environmental impacts caused by intensive swine farming and the economic importance and growth of this activity, this study evaluated environmental management practices on swine farms located in the state of São Paulo/Brazil. In order to accomplish this, exploratory interviews were conducted with the managers or owners of 37 randomly selected farms. The resulting data was then used to create a questionnaire that contained eight questions, and to also create an electronic database containing questions and answers. Weights, varying from 1 to 10 based upon their importance in preventing or mitigating
\end{abstract}


environmental degradation, were assigned for each process carried out on the farm. The farms were then classified as satisfactory, satisfactory with restrictions and unsatisfactory, if their scores were greater than or equal to 70 points, between 51 and 69 points or lower than 51 points, respectively. The results showed that approximately $62 \%$ of the swine farms investigated were considered unsatisfactory, since their average score was 43.61. Approximately $11 \%$ and $27 \%$ were deemed satisfactory with restrictions and satisfactory, respectively, since their scores were 59.50 and 84.40. For items considered important, such as the use of biodigesters and compost, $51.35 \%$ used no biodigesters and $67.55 \%$ and $62.15 \%$, respectively, used no compost or their practices were unsatisfactory. The need for incentive programs to improve swine waste management on farms in São Paulo State was therefore made evident.

Keywords: biodigester, composting, swine waste.

\section{INTRODUÇÃO}

O Brasil é o quinto maior consumidor de carne suína do mundo e o quarto maior exportador deste produto (ABIPECS, 2014). A expectativa do mercado suinícola brasileiro para os anos vindouros é de crescimento, principalmente da exportação (ABCS, 2014).

A produção intensiva da suinocultura e a constante busca pelo incremento de produtividade contribuem de forma decisiva no aumento da poluição por dejetos, o que têm causado desequilíbrios ecológicos em diversos municípios brasileiros.

Segundo a ISO 14.001, que é uma norma internacionalmente aceita, Sistema de Gestão Ambiental é uma estrutura desenvolvida para que uma organização possa consistentemente controlar seus impactos significativos sobre o meio ambiente e melhorar continuamente as operações e negócios. Particularmente, Sistema de Gestão Ambiental em Suinocultura (SGAS) pode ser definido como um conjunto de atividades econômicas e sociais que utilizam os recursos naturais de forma racional com o uso de tecnologias que proporcionem a produção de suínos de forma sustentável com a minimização dos impactos ambientais gerados principalmente pela elevada produção de efluentes e de gases do efeito estufa (Honeyman, 1996). Neste contexto, o crescimento da suinocultura demandará maior investimento, principalmente, em SGAS, requisito fundamental para a conquista de mercados internacionais.

Um suíno produz em média 2,35 kg de efluente sólido por dia, e quando se considera o dejeto sólido associado à urina, esse total se eleva para $5,80 \mathrm{~kg}$, fazendo de sistemas intensivos de produção com alta densidade de animais por metro quadrado, uma atividade altamente poluidora (Beli et al., 2010).

A maior parte do impacto ambiental gerado pela suinocultura provém da falta do manejo adequado dos resíduos sólidos (Williams, 2008) e líquidos gerados pela atividade, como a produção de efluentes com alta carga orgânica que é lançada em corpos d'água e que podem chegar aos lençóis freáticos, o que causa a poluição dos recursos hídricos da região em torno da granja; a poluição do ar e a destruição da camada de ozônio majoritariamente ocasionada pela emissão de gás metano e óxido nitroso (Barbosa e Langer, 2011).

Apesar disso, há medidas que podem ser tomadas em um SGAS a fim de mitigar os impactos gerados pela atividade, como a implantação de biodigestores (Vanotti et al., 2007), compostagem e politica de recursos hídricos com economia de água de consumo e consequente redução de produção de efluentes (Berto e Miranda, 2007). Entretanto, o conceito de SGAS ainda é novo na produção de suínos, e os componentes que o constituem são poucos aplicados na suinocultura tecnificada de forma satisfatória, o que faz com que a crescente exigência do consumidor interno como externo sobre a qualidade de produção da carne suína brasileira, uma mudança de paradigma por parte dos produtores. 
O Estado de São Paulo é o $7^{\circ}$ maior produtor de carne suína do país, com 85.406 matrizes alojadas (APCS, 2014). Tais números, juntamente com o histórico nacional da falta de cuidado com os impactos ambientais gerados pela atividade suinícola acabam por justificar a necessidade do desenvolvimento de um trabalho que apresente um diagnóstico do que vem sendo feito pelos produtores em relação ao SGAS em granjas do Estado de São Paulo.

Tendo em vista o potencial poluidor da atividade suinícola, o seu crescimento, a sua importância econômica e poucos estudos de diagnóstico de SGAS, este trabalho teve por objetivo avaliar o SGAS em granjas de suínos do Estado de São Paulo.

\section{MATERIAL E MÉTODOS}

O trabalho foi efetuado em 37 granjas de suínos tecnificadas de ciclo completo do Estado de São Paulo escolhidas de forma aleatória (Figura 1). A pesquisa foi realizada durante os meses de outubro de 2013 a maio de 2014, com 51.030 matrizes investigadas, que representou $60 \%$ do total de matrizes alojadas no Estado de São Paulo (APCS, 2014).

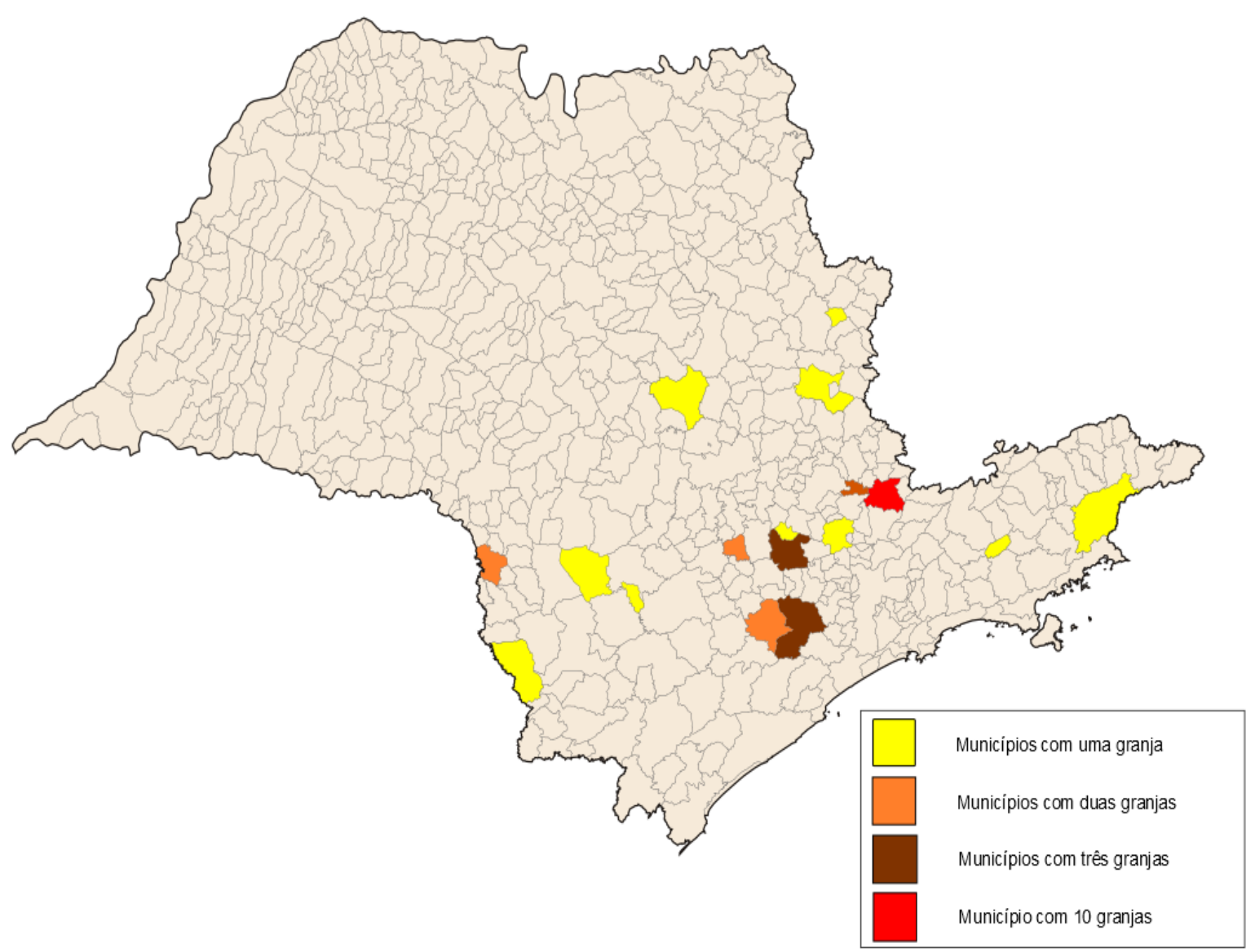

Figura 1. Mapa geopolítico do Estado de São Paulo e os respectivos municípios onde estavam localizadas as granjas pesquisadas.

Para a coleta de informações a respeito do SGAS nas granjas avaliadas e seu armazenamento foi elaborado um banco de dados eletrônico com a utilização do programa Google drive ${ }^{\circledR}$. Neste banco de dados foi inserido um questionário desenvolvido conforme metodologia proposta por Soto et al. (2006) e adaptada para esta investigação a fim de obter informações a respeito do SGAS nas respectivas granjas. 
Foram elaboradas oito questões abertas e fechadas para que as mesmas pudessem abranger todos os itens possíveis de estarem presentes em um SGAS e assim classificar os respectivos quesitos. As perguntas versavam sobre a existência ou não de tratamento de dejetos sólidos e carcaças por sistema de compostagem, uso de tratamento do efluente por sistema de lagoa anaeróbia integrada com a utilização da tecnologia de biodigestor, gestão de recursos hídricos com economia de água, planejamento de compras ecoeficientes (produtos produzidos com menor consumo de recursos naturais, espaço físico e menor geração de poluentes), gestão de resíduos sólidos de serviços de saúde animal, licenciamento e certificação ambiental, outorga de uso e lançamento de efluentes e geração ou não de produtos de valor agregado a partir dos diferentes sistemas de tratamento de dejetos sólidos e efluentes nas granjas investigadas.

Para cada questão foram atribuídos pesos distintos de um a 10 (Soto et al., 2006), de acordo com a importância e o impacto ambiental de cada item realizado ou não pela granja, e variando de dois (para a presença de produto com valor agregado resultante de algum processo) a 10 (atribuído aos itens considerados fundamentais para um eficiente SGAS). Neste trabalho as granjas foram classificadas em três categorias, tanto na somatória de todos os itens avaliados, como também de forma individual de cada quesito presente ou não no SGAS em: insatisfatórias com pontuação abaixo de 50 pontos, satisfatórias com restrição, entre 51 e 70 pontos e satisfatórias com pontuação acima ou igual a 70 pontos (Soto et al., 2006).

O questionário foi aplicado por meio de entrevistas diretamente com o gerente e ou proprietário das granjas investigadas e os resultados analisados com a utilização do software BrOffice Calc.

\section{RESULTADOS E DISCUSSÃO}

Na Tabela 1, estão apresentados os resultados totais obtidos em relação à pontuação nos SGAS das 37 granjas investigadas.

Tabela 1. Classificação das granjas em relação ao sistema de gestão ambiental empregado e as respectivas porcentagens, pontuações totais e médias obtidas.

\begin{tabular}{lccccc}
\hline Classificação & $\mathbf{N}^{\circ}$ de granjas & $\mathbf{\%}$ & MEP & MAP & PM \\
\hline Insatisfatórias & 23 & 62,16 & 23 & 49 & 43,61 \\
$\begin{array}{l}\text { Satisfatórias com } \\
\text { restrição }\end{array}$ & 04 & 10,81 & 56 & 62 & 59,50 \\
Satisfatórias & 10 & 27,03 & 73 & 97 & 84,40 \\
\hline Total & $\mathbf{3 7}$ & $\mathbf{1 0 0 , 0 0}$ & $\mathbf{5 0 , 6 6}$ & $\mathbf{6 9 , 3 3}$ & $\mathbf{6 2 , 5 0}$ \\
\hline
\end{tabular}

Nota: $\mathrm{N}^{\circ}$ - número; \% - porcentagem; MEP- menor pontuação; MAP- maior pontuação, PM- pontuação média.

Foram classificadas como insatisfatórias $23(62,16 \%)$ granjas do total de 37 avaliadas, com valor médio de 43,61 pontos, e satisfatórias com restrição, quatro $(10,81 \%)$, com valor médio de 59,50 pontos (Tabela1). Estes dois itens classificatórios juntos representaram $72,97 \%$ de granjas potencialmente geradoras de riscos ambientais, relacionados principalmente a disposição e destino inadequado de efluentes e resíduos sólidos no meio ambiente. Considerando as menores (23) e maiores (49) pontuações nas granjas classificadas como insatisfatórias, foram encontrados valores médios de 43,61 pontos, aquém do mínimo necessário para um SGAS que ofereça minimização de riscos ao meio ambiente. A maior 
pontuação média, obtida nas três classificações, apresentou valor de 69,33 pontos, considerado satisfatório com restrição (Tabela 1).

Das granjas consideradas como satisfatórias, obteve-se o resultado de 27,03\%, valor considerado baixo, quando se considera que nas 37 unidades investigadas o nível de tecnologia de produção zootécnica de suínos foi alto. Observa-se com estes resultados, que ainda persiste na maioria das unidades de produção de suínos do Estado de São Paulo avaliadas, uma maior preocupação com resultados zootécnicos, relacionados principalmente a maximização do desempenho produtivo e reprodutivo dos planteis, e a gestão ambiental ficou em segundo plano na lista de prioridades da administração do empreendimento.

Em relação à licença e certificação ambiental, somente $10(27,03 \%)$ granjas classificadas como satisfatórias eram licenciadas e certificadas (Tabelas 1 e 2) e geravam no SGAS pelo menos um produto de valor agregado como: biofertilizante, energia elétrica e ou térmica e créditos de carbono. Para a outorga de uso e captação de água e lançamento de efluentes, $11(29,72 \%)$ granjas possuíam o documento (Tabela 2). Estes resultados reforçam a necessidade por parte dos órgãos governamentais do Estado de São Paulo, o desenvolvimento de legislação mais rigorosa e especifica para a atividade suinícola. Ela deve prever a obrigatoriedade de SGAS que sejam capazes de sequestrar a produção de gás metano (Secco et al., 2014) e tratar os resíduos sólidos de modo que os tornem produtos de baixo impacto sanitário e ambiental (Daga et al., 2008) e que gerem valor agregado, como por exemplo, a tecnologia de biodigestor associada a um motogerador de energia elétrica (Ferrarez et al., 2010) e de compostagem (Bernal et al., 2009). Aliado a esta obrigatoriedade, é necessário que seja construída uma estrutura que ofereça maior poder de fiscalização e abrangência, com punição eficiente para as granjas infratoras.

Na Tabela 2 estão apresentados os resultados obtidos em relação ás 37 granjas investigadas e a respectiva classificação por questão relacionada ao SGAS.

Tabela 2. Resultados obtidos em relação às 37 granjas investigadas e a respectiva classificação por questão relacionada ao sistema de gestão ambiental em suinocultura. Valores expressos numericamente e em porcentagem $(\%)$.

\begin{tabular}{|c|c|c|c|c|}
\hline Questão & AS & IN & SR & SA \\
\hline Compostagem de carcaças e placentas & $\begin{array}{l}18 \\
(48,64 \%)\end{array}$ & $\begin{array}{l}05 \\
(13,51 \%)\end{array}$ & $\begin{array}{l}04 \\
(10,81 \%)\end{array}$ & $\begin{array}{l}10 \\
(27,03 \%)\end{array}$ \\
\hline Compostagem de dejetos sólidos & $\begin{array}{l}11 \\
(29,72 \%)\end{array}$ & $\begin{array}{l}14 \\
(37,83 \%)\end{array}$ & $\begin{array}{l}02 \\
(5,40 \%)\end{array}$ & $\begin{array}{l}10 \\
(27,03 \%)\end{array}$ \\
\hline Biodigestor & $\begin{array}{l}19 \\
(51,35 \%)\end{array}$ & $\begin{array}{l}07 \\
(18,91 \%)\end{array}$ & $\begin{array}{l}01 \\
(2,70 \%)\end{array}$ & $\begin{array}{l}10 \\
(27,03 \%)\end{array}$ \\
\hline $\begin{array}{l}\text { Gestão de resíduos sólidos de serviços de } \\
\text { saúde animal }\end{array}$ & $\begin{array}{l}13 \\
(35,13 \%)\end{array}$ & $\begin{array}{l}13 \\
(35,13 \%)\end{array}$ & $\begin{array}{l}03 \\
(8,10 \%)\end{array}$ & $\begin{array}{l}08 \\
(21,62 \%)\end{array}$ \\
\hline Planejamento de compras ecoeficientes & $\begin{array}{l}25 \\
(67,56 \%)\end{array}$ & $\begin{array}{l}01 \\
(2,70 \%)\end{array}$ & $\begin{array}{l}03 \\
(8,10 \%)\end{array}$ & $\begin{array}{l}08 \\
(21,62 \%)\end{array}$ \\
\hline $\begin{array}{l}\text { Gestão de recursos hídricos como economia } \\
\text { de água de consumo }\end{array}$ & $\begin{array}{l}18 \\
(48,64 \%)\end{array}$ & $\begin{array}{l}11 \\
(29,72 \%)\end{array}$ & $\begin{array}{l}01 \\
(2,70 \%)\end{array}$ & $\begin{array}{l}07 \\
(18,91 \%)\end{array}$ \\
\hline Licença e certificação ambiental & $\begin{array}{l}27 \\
(72,98 \%)\end{array}$ & $\begin{array}{l}00 \\
\text { (zero) }\end{array}$ & $\begin{array}{l}00 \\
\text { (zero) }\end{array}$ & $\begin{array}{l}10 \\
(27,03 \%)\end{array}$ \\
\hline $\begin{array}{l}\text { Outorga de uso e captação de água e } \\
\text { lançamento de efluentes }\end{array}$ & $\begin{array}{l}26 \\
(70,27 \%)\end{array}$ & $\begin{array}{l}00 \\
\text { (zero) }\end{array}$ & $\begin{array}{l}00 \\
(\text { zero })\end{array}$ & $\begin{array}{l}11 \\
(29,72 \%)\end{array}$ \\
\hline
\end{tabular}

Nota: AS-Ausência, IN- Insatisfatória, SR- Satisfatória com restrição, SA- Satisfatória . 
Para o item compostagem de carcaças e placenta, considerando a soma das granjas que não praticavam esta tecnologia $(48,64 \%)$ ou a faziam de forma insatisfatória $(13,51 \%)$ (Tabela 2), obteve-se o resultado de $62,15 \%$. Evidenciou-se neste quesito, que apesar de poder ser facilmente cumprido de forma satisfatória pelo seu baixo custo de implantação e simplicidade operacional com a geração de resultados positivos tanto no aspecto ambiental como sanitário (Soto et al., 2010), ainda não é uma prática realizada pela maioria das granjas.

Em relação à compostagem de dejetos sólidos, 29,72\% das granjas avaliadas apresentaram ausência do sistema e 37,83\%, foram classificadas como insatisfatórias, somando $67,55 \%$. Estes resultados são preocupantes, devido ao fato do alto risco de contaminação ambiental que a ausência desta pratica ou a sua utilização de forma insatisfatória pode representar para o meio ambiente (Kunz et al., 2008). Ademais, a produção de compostagem a partir de resíduos sólidos podem gerar outros lucros como a produção de biofertilizante, um produto de valor agregado para a suinocultura (Sardá et al., 2010).

Para o quesito biodigestor, $51,35 \%$ das granjas avaliadas ainda não dispunham desta tecnologia para o SGAS, considerada como protagonista para o tratamento de efluentes, sequestro de gás metano (Vanotti et al., 2008) e produção de biocombustível para a geração de produtos de valor agregado como energia elétrica e térmica (Cervi et al., 2010).

Em relação à gestão de resíduos sólidos de serviços de saúde animal, considerando a soma das granjas que não praticavam este tipo de atividade, ou faziam de forma insatisfatória, obteve-se o valor de 70,26\%, o que demonstrou que a prática de gerenciamento deste tipo de resíduo ainda é incipiente nos sistemas intensivos de produção animal (Reis et al., 2013).

No item planejamento de compras ecoeficientes, considerando também a soma das granjas que não praticavam este tipo de atividade, ou faziam de forma insatisfatória observou-se que $70,26 \%$ das granjas ainda não realizavam esta prática ou a faziam de forma insatisfatória, o que reforça a necessidade de todos os setores envolvidos em gestão ambiental em suinocultura implantarem esta filosofia de trabalho. Observou-se também o pouco conhecimento por parte dos suinocultores desta prática, ainda distante do seu cotidiano na atividade suinícola, o que mostra a necessidade de processos de capacitação de gestão ambiental, em todos os seus componentes.

Para o quesito gestão de recursos hídricos como economia de água de consumo, quase metade das granjas avaliadas $(48,64 \%)$ não tinham esta ação contemplada no SGAS e $29,72 \%$ realizavam de forma insatisfatória. Este fato gera preocupação ambiental pelo fato da água ser um recurso natural escasso (Mckeon, 2008) e quanto maior o seu consumo no sistema produtivo de suínos, maior será o volume de efluentes produzido diariamente, com aumento de custos operacionais para o seu tratamento adequado (Palhares e Calijuri, 2007).

\section{CONCLUSÕES}

Das granjas de suínos avaliadas em relação ao SGAS, $62,16 \%$ foram consideradas insatisfatórias e classificadas como potencialmente geradoras de riscos ambientais. Este resultado reforça a necessidade do real cumprimento da legislação, com maior controle por parte das autoridades a fim de evitar a deterioração ambiental no entorno da atividade suinícola.

Dos itens considerados importantes em um SGAS, 51,35\% e 67,55\% respectivamente, das granjas investigadas, não dispunham da tecnologia de biodigestor e não praticavam a compostagem de resíduos sólidos e de carcaças ou as faziam de forma insatisfatória.

A preocupação com a gestão do uso eficiente da água de consumo na atividade suinícola paulista, ainda é incipiente. Há a necessidade de um processo de capacitação e conscientização continuado aos proprietários e funcionários que trabalham com suinocultura, em virtude do potencial dano que esta gestão inadequada pode gerar ao meio ambiente. 


\section{REFERÊNCIAS}

ASSOCIAÇÃO BRASILEIRA DE CRIADORES DE SUÍNOS - ABCS. Estatísticas 2014. Disponível em: <http://www.abcs.org.br/>. Acesso em: 12 jun. 2014.

ASSOCIAÇÃO BRASILEIRA DA INDÚSTRIA PRODUTORA E EXPORTADORA DE CARNE SUÍNA - ABIPECS. Estatísticas 2014. Disponível em:

http://www.abipecs.com.br/. Acesso em: 12 jun. 2014.

ASSOCIAÇÃO PAULISTA DE CRIADORES DE SUÍNOS - APCS. Estatísticas, 2014. Disponível em: <http://www.apcs.com.br/portal/> . Acesso em: 12 jun. 2014.

BARBOSA, G.; LANGER, M. Uso de biodigestores em propriedades rurais: uma alternativa à sustentabilidade ambiental. Unoesc \& Ciência ACSA, v. 2, n. 1, p. 87-96, 2011.

BELI, E.; HUSSAR, G. J.; HUSSAR, D. H. Redução de DQO e turbidez de efluente de uma unidade suinícola empregando Reator Anaeróbio Compartimentado (RAC) seguido de filtro biológico e filtro de areia. Engenharia Ambiental, v. 7, n. 1, p. 5-19, 2010.

BERNAL, M. P.; ALBURQUERQUE, J. A.; MORAL, R. Composting of animal manures and chemical criteria for compost maturity assessment. A review. Bioresource Technology, v. 10, n. 22, p. 5444-5453, 2009. http://dx.doi.org/10.1016/j.biortech.2008.11.027

BERTO, J. L.; MIRANDA, C. R. Sustentabilidade ambiental das propriedades suinícolas da microrregião do Meio Oeste Catarinense: uma avaliação com base no balanço de nutrientes. Revista Brasileira de Agroecologia, v. 2, n. 1, p. 1589-1592, 2007.

CERVI, R. G.; ESPERANCINI, M. S. T.; BUENO, O. C. Viabilidade econômica da utilização do biogás produzido em granja suinícola para geração de energia elétrica. Engenharia Agrícola, v. 30, n. 5, p. 831-844, 2010.

DAGA, J.; CAMPOS, A. T.; FEIDEN, A.; KLOSOWSKI, E. S.; CÂMARA, R. J. Análise da adequação ambiental e manejo dos dejetos de instalações para suinocultura em propriedades na região oeste do Paraná. Engenharia Agrícola, v. 27, n. 3, p.1-11, 2008. http://dx.doi.org/10.1590/S0100-69162007000400001

FERRAREZ, A. H.; FILHO, D. O.; TEIXEIRA, C. A. Independência energética de granja suinícola a partir do uso de biogás. Engenharia na Agricultura, v. 18, n. 3, p. 248-257, 2010.

HONEYMAN, M. S. Sustainability issues of U. S. swine production. Journal of Animal Science, v. 74, p. 1410-1417, 1996.

KUNZ, A.; BORTOLI, M.; HIGARASHI, M. M. Avaliação do manejo de diferentes substratos para compostagem de dejetos líquidos de suínos. Acta Ambiental Catarinense, v. 5. n. 1/2, p. 8-19, 2008.

MCKEON, M. Cut your slurry costs: new calculations show the difference in menure handling water economies reduce the volume for disposal. Pig International, v. 5, p. 22-24, 2008.

PALHARES, J. C. P.; CALIJURI, M. C. Caracterização dos afluentes e efluentes suinícolas em sistemas de crescimento/terminação e qualificação do seu impacto ambiental. Ciência Rural, v. 37, n. 2, p. 502-509, 2007. http://dx.doi.org/10.1590/S010384782007000200032 
REIS, M. A.; RANGEL, M. L.; MATTOS, C. M.; FRANKE, C. R. Conhecimento, prática e percepção sobre o gerenciamento de resíduos de serviços de saúde em estabelecimentos médicos veterinários de Salvador, Bahia. Revista Brasileira de Saúde e Produção Animal, v. 14, n.2 p. 287-298, 2013.

SARDÁ, L. G.; HIGARASHI, M. M.; MUlleR, S.; OliVEIRA, P. A.; COMIN, J. J. Redução de emissão de $\mathrm{CO}_{2}, \mathrm{CH}_{4}$ e $\mathrm{H}_{2} \mathrm{~S}$ através da compostagem de dejetos de suínos. Revista Brasileira de Engenharia Agrícola e Ambiental, v. 9, p. 1008-1013, 2010.

SECCO, M. A. G.; KUNZ, A.; EDWIGES, T.; JUNIOR, A. M.; FRIGO, E. P.; ALVES, E. J. Performance of up-flow anaerobic digester in solids removal and biogas production. Journal of Food, Agriculture \& Environment, v. 12, n. 2, p. 1135-1139, 2014.

SOTO, F. R. M.; RISSETO, M. R.; CAZZOLA, C. P. B. Proposta e análise crítica de um protocolo de inspeção e de condições sanitárias em supermercados do município de Ibiúna- SP. Revista Brasileira de Epidemiologia, v. 9, n. 2, p. 235-241, 2006.

SOTO, F. R. M.; COELHO, C. P.; BENITES, N. R.; BONAMIN, L.V.; MELVILlE, P. A. Elimination of $E$. coli from piglet carcases using an on-farm composting system. Veterinary Records, v. 166, p. 564-565, 2010.

VAnOTTI, M. B.; SzOGI, A. A.; HUNT, P. G.; Millner, P. D.; HUMENIK, F. J. Development of environmentally superior treatment system to replace anaerobic swine lagoons in the USA. Bioresource Technology, v. 98, n. 17, p. 3184-3194, 2007. http://dx.doi.org/10.1016/j.biortech.2006.07.009

VANOTTI, M. B.; SZOGI, A. A.; VIVES, C. A. Greenhouse gas emission reduction and environmental quality improvement from implementation of aerobic waste treatment systems in swine farms. Waste Management, v. 28, n. 4, p. 759-766, 2008. http://dx.doi.org/10.1016/j.wasman.2007.09.034

WILLIAMS, C. M. M. Technologies to mitigate environmental impact of swine production. Revista Brasileira de Zootecnia, v. 37, p. 253-259, 2008. http://dx.doi.org/10.1590/S1516-35982008001300029 